\title{
Root-Knot Nematodes (Meloidogyne spp.) Parasitizing Resistant Tobacco Cultivars in Southern Brazil
}

Jerônimo Vieira de Araújo Filho, Faculdade de Agronomia Eliseu Maciel, Universidade Federal de Pelotas, Fitossanidade, Campus Capão do Leão, 96010900, Pelotas, RS, Brazil; Andressa Cristina Zamboni Machado, Instituto Agronômico do Paraná, 86047-902, Londrina, PR, Brazil; Leandro José Dallagnol, Faculdade de Agronomia Eliseu Maciel, Universidade Federal de Pelotas; and Luís Eduardo Aranha Camargo, Departamento de Fitopatologia e Nematologia, Escola Superior de Agricultura "Luiz de Queiroz", 13418-900, Piracicaba, SP, Brazil

\begin{abstract}
de Araújo Filho, J. V., Machado, A. C. Z., Dallagnol, L. J., and Camargo, L. E. A. 2016. Root-knot nematodes (Meloidogyne spp.) parasitizing resistant tobacco cultivars in southern Brazil. Plant Dis. 100:1222-1231.

Our study surveyed Meloidogyne spp. from tobacco cultivars in Brazil carrying the $R k$ gene, which confers resistance to Meloidogyne incognita races 1 and 3. Identification of Meloidogyne populations from 39 tobacco fields was based on the analysis of esterase phenotypes, perineal patterns, and 18S-internal transcribed spacer (ITS)1-5.8S ribosomal RNA sequences. Biometric characterization and differential host tests of isolates were determined as well. We detected M. incognita, M. javanica, M. enterolobii, $M$. arenaria, and $M$. inornata in $18(46.2 \%), 16(41 \%), 10(25.6 \%)$, $2(5.1 \%)$, and $1(2.6 \%)$ samples, respectively. Mixtures of species were found in $25.6 \%$ of the samples. This is the first report of M. inornata

parasitizing tobacco in Brazil's southern region. Two morphological and biochemically unusual populations had host ranges and ITS1 sequences nearly identical to $M$. enterolobii and $M$. incognita, respectively. Pathogenic and biometric intraspecific variations were observed. Based on our results and considering the limited efficiency of the $R k$ gene, it is indispensable not only to search for resistance sources to $M$. incognita virulent strains but also to consider resistance to $M$. enterolobii, $M$. inornata, $M$. arenaria, and $M$. javanica in tobacco breeding programs. Changes in integrated management procedures should be considered to avoid increased crop damage in the future.
\end{abstract}

Tobacco (Nicotiana tabacum L.) is the main economic nonfood crop worldwide (Sinditabaco 2013). Brazil is the second leading world producer and the greatest exporter of tobacco. Total production during the 2011-12 growing season was approximately 737,000 metric tons; the southern region of Brazil accounted for $96 \%$ of this production. In Brazil, 200,000 small farms are involved in the production of tobacco, generating an annual income of U.S.\$2 billion (ABIFUMO 2013; Souza Cruz 2013). Tobacco production in Brazil is threatened by various pathogens due to a narrow genetic base of currently grown cultivars as well as intensive cropping practices. Among production-limiting pathogens, plant-parasitic nematodes are a concern among growers (Ferraz and Brown 2002). Several plant-parasitic nematode species have been reported to be associated with tobacco (Johnson et al. 2005) but Meloidogyne spp. are the most economically important, causing extensive yield losses of 15 to $28 \%$ (Díaz-Silveira and Herrera 1998; Shew and Lucas 1991).

In recent decades, Meloidogyne spp. control has been based on the use of resistant tobacco cultivars carrying a single gene with complete dominance, called $R k$ (Yi et al. 1998). This gene was transferred from $N$. tomentosa and confers resistance to races 1 and 3 of Meloidogyne incognita (Kofoid \& White) Chitwood and race 1 of M. arenaria (Neal) Chitwood (Shew and Lucas 1991). Despite this, Meloidogyne spp. are still a serious problem in Brazil. Changes in the composition of Meloidogyne spp. and M. incognita virulent strains induced by the compulsory and exclusive use of the gene $R k$ could explain this, as in other countries (Rich and Garcia 1985; Stanton et al. 1998).

Surveys in infested Brazilian tobacco-growing areas are scarce and very old. $M$. incognita, M. javanica (Treub) Chitwood, and M. arenaria have all been reported in Brazil (Johnson et al. 2005; Zem et al. 1985). A recent report noted the occurrence of $M$. enterolobii

Corresponding author: J. V. de Araújo Filho; E-mail: jerofilho@usp.br

Accepted for publication 1 February 2016.

http://dx.doi.org/10.1094/PDIS-03-15-0341-RE

(C) 2016 The American Phytopathological Society
Yang \& Eisenback ( = M. mayaguensis Rammah \& Hirschmann) (Gomes et al. 2008). Other species were described or revalidated at this time (Moens et al. 2010). These identifications were based only on morphology and included overlapping intraspecific and intrapopulation characteristics commonly observed in Meloidogyne spp. (Brito et al. 2004; Carneiro et al. 2000; Cofcewicz et al. 2004), potentially resulting in misidentifications. For this reason, the integration of classic, biochemical, and molecular tools for effective diagnosis has often been recommended (McClure et al. 2012).

The objectives of this research were to (i) document the occurrence of Meloidogyne spp. in resistant tobacco cultivars $(R k)$ in the major tobacco-producing regions of Brazil, with identification based on integrated analyses of esterase (Est phenotypes), perineal patterns, and partial sequencing of the $18 \mathrm{~S}$-internal transcribed spacer (ITS) 1-5.8S ribosomal RNA (rRNA) region (ITS1-rRNA); (ii) analyze the phylogenetic relationships among collected Meloidogyne spp.; (iii) characterize isolates biometrically; and (iv) determine the races of Meloidogyne present in Brazil. To our knowledge, this is the first survey in Brazilian tobacco-growing areas based on the integration of biochemical, molecular, and morphological approaches.

\section{Materials and Methods}

Collection and maintenance of Meloidogyne populations and isolates. Roots samples were collected in 39 naturally infested tobacco fields comprising several resistant cultivars (Table 1). The sampling was made in a targeted way: only symptomatic plants were collected in each field. All samples were placed in plastic bags and transported to the laboratory. The Meloidogyne spp. populations were established and maintained (1 year) on susceptible 'Santa Clara' tomato (Solanum lycopersicum) from specimens obtained by the sodium hypochlorite method (Hussey and Barker 1973). Plants were grown under greenhouse conditions at temperatures of 25 to $30^{\circ} \mathrm{C}$.

Monospecific isolates from each population (Laboratório de Genética Molecular [LGM] isolates) were established from a single egg mass, inoculated onto Santa Clara tomato, and maintained as described above. These isolates were subsequently used for the biometric studies and differential host tests. Due to the parthenogenetic reproduction of theses Meloidogyne spp. (Ferraz and Brown 2002; Trudgill and Blok 2001), each isolate was considered a clonal line. 
Later, the specific identity of each isolate was confirmed again by Est phenotypes. When more than one isolate was obtained from a mixed population, we assigned different numbering to the codes (i.e., LGM 07.1 and LGM 07.2).
Morphological and biochemical analyses of Meloidogyne populations. At least 10 perineal patterns from each population cultured in the greenhouse were studied under a light microscope (LM) using standard procedures (Hartman and Sasser 1985). All slides

Table 1. Geographic origin, codes for populations, esterase (Est) phenotypes, and GenBank accession numbers of Meloidogyne spp. populations collected from tobacco fields in Brazil planted with cultivars containing $R k$ resistance

\begin{tabular}{|c|c|c|c|c|}
\hline Meloidogyne sp., city, state & Cultivar & Codes $^{b}$ & Est phenotypes & Accession number ${ }^{c}$ \\
\hline \multicolumn{5}{|l|}{ Meloidogyne incognita } \\
\hline Araranguá, SC & CSC 444 & IPR LGM 01 & $\mathrm{I}_{1}$ and $\mathrm{I}_{2}$ & KF053005 \\
\hline Içará, SC & CSC 467 & IPR LGM 02 & $\mathrm{I}_{1}$ & KF053006 \\
\hline Araranguá, SC & CSC 444 & IPR LGM 06 & $\mathrm{I}_{2}$ & KF053009 \\
\hline Sombrio, SC & CSC 467 & IPR LGM 07d & $\mathrm{I}_{1}$ & KF053010 \\
\hline Sombrio, SC & CSC 405 & IPR LGM 09 & $\mathrm{I}_{2}$ & KF053011 \\
\hline Sombrio, SC & CSC 444 & IPR LGM $10^{\mathrm{d}}$ & $\mathrm{I}_{1}$ & KF053012 \\
\hline Venâncio Aires, RS & CSC 444 & IPR LGM 14 & $\mathrm{I}_{2}$ & KF053016 \\
\hline Venâncio Aires, RS & CSC 401 & IPR LGM 16 & $\mathrm{I}_{1}$ & $\ldots$ \\
\hline Apiúna, SC & CSC 467 & IPR LGM $32^{d}$ & $\mathrm{I}_{1}$ & $\ldots$ \\
\hline Ituporanga, SC & CSC 405 & IPR LGM 35 & $\mathrm{I}_{2}$ & KF053028 \\
\hline Mercedes, PR & BRAVO 702 & IPR LGM 36 & $\mathrm{I}_{1}$ & KF053029 \\
\hline Mercedes, PR & BRAVO 702 & IPR LGM 39 & $\mathrm{I}_{2}$ and $\mathrm{I}_{1}$ & KF053032 \\
\hline Mercedes, PR & BRAVO 702 & IPR LGM 40 & $\mathrm{I}_{1}$ & KF053033 \\
\hline Marechal Cândido Rondon, PR & BRAVO 702 & IPR LGM 41 & $\mathrm{I}_{1}$ and $\mathrm{I}_{2}$ & KF053034 \\
\hline Marechal Cândido Rondon, PR & BRAVO 702 & IPR LGM 42 & $\mathrm{I}_{1}$ & KF053035 \\
\hline Marechal Cândido Rondon, PR & BRAVO 702 & IPR LGM $43^{d}$ & $\mathrm{I}_{1}$ & KF053036 \\
\hline Missol, PR & BRAVO 702 & IPR LGM $44^{\mathrm{d}}$ & $\mathrm{I}_{1}$ & KF053037 \\
\hline Mercedes, PR & BRAVO 702 & IPR LGM $45^{\mathrm{d}}$ & $\mathrm{I}_{1}$ & $\ldots$ \\
\hline \multicolumn{5}{|l|}{ M. javanica } \\
\hline Içará, SC & CSC 405 & IPR LGM 05 & $\mathrm{~J} 3$ & $\ldots$ \\
\hline Sombrio, SC & CSC 467 & IPR LGM $07^{d}$ & $\mathrm{~J} 3$ & $\ldots$ \\
\hline Araranguá, SC & CSC 444 & IPR LGM 08 & $\mathrm{~J} 3$ & $\ldots$ \\
\hline Sombrio, SC & CSC 444 & IPR LGM $10^{\mathrm{d}}$ & $\mathrm{J} 3$ & $\ldots$ \\
\hline Vale do Sol, RS & CSC 467 & IPR LGM 12 & $\mathrm{~J} 3$ & KF053014 \\
\hline Vale do Sol, RS & CSC 439 & IPR LGM 13 & $\mathrm{~J} 3$ & KF053015 \\
\hline Rio Pardo, RS & CSC 401 & IPR LGM $17^{d}$ & $\mathrm{~J} 3$ & $\ldots$ \\
\hline Rio Pardo, RS & CSC 416 & IPR LGM 18 & $\mathrm{~J} 3$ & KF053017 \\
\hline Vera Cruz, RS & CSC 444 & IPR LGM 21 & $\mathrm{~J} 3$ & KF053018 \\
\hline Presidente Nereu, SC & CSC 405 & IPR LGM $23^{\mathrm{d}}$ & $\mathrm{J} 3$ & KF053019 \\
\hline Agronômica, SC & CSC 444 & IPR LGM $29^{d}$ & $\mathrm{~J} 3$ & $\ldots$ \\
\hline Agrolândia, SC & CSC 416 & IPR LGM 33 & $\mathrm{~J} 3$ & KF053026 \\
\hline Agronômica, SC & CSC 405 & IPR LGM $34^{\mathrm{d}}$ & $\mathrm{J} 3$ & KF053027 \\
\hline Marechal Cândido Rondon, PR & BRAVO 702 & IPR LGM 37 & $\mathrm{~J} 3$ & KF053030 \\
\hline Marechal Cândido Rondon, PR & BRAVO 702 & IPR LGM $43^{d}$ & $\mathrm{~J} 3$ & $\ldots$ \\
\hline Missol, PR & BRAVO 702 & IPR LGM $44^{\mathrm{d}}$ & $\mathrm{J} 3$ & $\ldots$ \\
\hline \multicolumn{5}{|l|}{ M. enterolobii } \\
\hline Treze de Maio, SC & CSC 404 & IPR LGM 03 & VS1-S1 & KF053007 \\
\hline Pedras Grandes, SC & CSC 438 & IPR LGM 04 & VS1-S1 & KF053008 \\
\hline Treze de Maio, SC & CSC 404 & IPR LGM 11 & VS1-S1 & KF053013 \\
\hline Presidente Nereu, SC & CSC 405 & IPR LGM $23^{d}$ & VS1-S1 & $\ldots$ \\
\hline Ascurra, SC & CSC 439 & IPR LGM 26 & VS1-S1 & KF053020 \\
\hline Ascurra, SC & CSC 439 & IPR LGM 28 & VS1-S1 & KF053022 \\
\hline Agronômica, SC & CSC 444 & IPR LGM $29^{d}$ & VS1-S1 & KF053023 \\
\hline Agronômica, SC & CSC 444 & IPR LGM 30 & VS1-S1 & KF053024 \\
\hline Apiúna, SC & CSC 467 & IPR LGM $32^{\mathrm{d}}$ & VS1-S1 & $\ldots$ \\
\hline Agronômica, SC & CSC 405 & IPR LGM $34^{\mathrm{d}}$ & VS1-S1 & $\ldots$ \\
\hline \multicolumn{5}{|l|}{ M. arenaria } \\
\hline Rio Pardo, RS & CSC 401 & IPR LGM $17^{d}$ & $\mathrm{~A} 2$ & $\ldots$ \\
\hline Ituporanga, SC & CSC 405 & IPR LGM 31 & A2 & KF053025 \\
\hline \multicolumn{5}{|l|}{ M. inornata } \\
\hline Mercedes, PR & BRAVO 702 & IPR LGM $45^{\mathrm{d}}$ & $\mathrm{I} 3$ & KF053038 \\
\hline \multicolumn{5}{|l|}{ Meloidogyne sp. 1} \\
\hline Vidal Ramos, SC & CSC 405 & IPR LGM 27 & $\mathrm{~F} 2^{\mathrm{e}}$ & KF053021 \\
\hline \multicolumn{5}{|l|}{ Meloidogyne sp. 2} \\
\hline Marechal Cândido Rondon, PR & BRAVO 702 & IPR LGM 38 & $\mathrm{~F} 3^{\mathrm{e}}$ & KF053031 \\
\hline
\end{tabular}


were deposited (Table 1) at the Instituto Agronômico do Paraná [IPR], Londrina, Paraná State, Brazil. The Est phenotypes were determined using protein extract from 18 young egg-laying females from each population. Females were placed in a hematocrit containing $5 \mu \mathrm{l}$ of extraction solution (Carneiro et al. 2000), macerated, and transferred to wells on polyacrylamide gel with $4 \%$ stacking $(\mathrm{pH}$ 6.8 ) and $7.5 \%$ separating $(\mathrm{pH}$ 8.9) gel using Tris-glycine buffer (pH 8.9). Homogenates of the $M$. javanica isolate IPR 81 (phenotype $\mathrm{J} 3$, relative mobility rate $[\mathrm{Rm}]=1.0,1.3$, and 1.4 ) was used as a known reference. Electrophoresis was carried out in a Mini Protean III (Bio-Rad Laboratories) unit at $4^{\circ} \mathrm{C}$ (Brito et al. 2008). Gels were stained with $\alpha$-naphthyl acetate (Carneiro et al. 2000) and Rm was calculated for each gel.

DNA extraction, polymerase chain reaction, sequencing, and phylogenetic analysis of Meloidogyne populations. DNA was extracted from single females according to Stanton et al. (1998) and stored at $-20^{\circ} \mathrm{C}$. The polymerase chain reaction (PCR) assays for ITS1-rRNA $(50 \mu \mathrm{l})$ were performed using Taq PCR Master Mix Kit (Promega Corp.) and the primers rDNA2 (5'-TTGATTACGTCCCTGC CCTTT-3') and rDNA1.58S (5'-ACGAGCCGAGTGATCCACCG-3') (Cherry et al. 1997). Taq PCR Master Mix Kit $(25 \mu \mathrm{l}), 1.5 \mu \mathrm{l}(0.3 \mathrm{mM})$ of each primer, $18 \mu \mathrm{l}$ of milli-Q water, and $4 \mu \mathrm{l}$ of total DNA were placed in a microfuge tube. The thermal cycler was programmed as follows: $94^{\circ} \mathrm{C}(2 \mathrm{~min})$ followed by 40 cycles of $94^{\circ} \mathrm{C}(1 \mathrm{~min}), 57^{\circ} \mathrm{C}$ ( $1 \mathrm{~min})$, and $72^{\circ} \mathrm{C}(2 \mathrm{~min})$.

DNA sequences were analyzed using the BLASTn megablast program (http://www.ncbi.nlm.nih.gov/blast/Blast.cgi) and deposited in GenBank (Table 1). The ITS1 sequences were aligned and edited using CLUSTAL X 2 (Thompson et al. 1997) and GeneDoc (Nicholas et al. 1997). Descriptive statistics, divergence estimates, and dendrograms were obtained using MEGA 5.1 (Tamura et al. 2011). The phylogenetic tree was constructed using the unweighted pair group method with arithmetic means algorithm with the maximumlikelihood model and complete deletion (1,500 replicates). Pratylenchus coffeae (AB053485.1 from Japan) was used as the outgroup taxon. An M. enterolobii sequence (JF309158.1 from Costa Rica) was included for comparison purposes.

Due to similarities between LGM 38 and M. incognita, we used the sequence-characterized amplified regions (SCAR) primer pair inc-K14 (5'-GGGATGTGTAAATGCTCCTG- ${ }^{\prime}$ ' and 5' ${ }^{\prime}$-CCCGCTACACCCT CAACTTC-3') (Randig et al. 2002) to differentiate these populations. The thermal cycler was programmed as follows: $94^{\circ} \mathrm{C}(5 \mathrm{~min})$, followed by 30 cycles of $94^{\circ} \mathrm{C}(30 \mathrm{~s}), 64^{\circ} \mathrm{C}(45 \mathrm{~s})$, and $70^{\circ} \mathrm{C}(1 \mathrm{~min})$; and a final incubation of $70^{\circ} \mathrm{C}(8 \mathrm{~min})$.

Scanning electron microscopy. Scanning electron microscopy (SEM) analysis was performed on partially dissected females obtained from the roots of tomato culture plants. After dissection, samples were transferred to glass vials containing $2 \mathrm{ml}$ of Karnovsky fixative solution $(2.5 \%$ [vol/vol] glutaraldehyde and $2.5 \%$ [ vol $/ \mathrm{vol}]$ paraformaldehyde in $0.05 \mathrm{M}$ sodium cacodylate buffer $+0.001 \mathrm{M}$ calcium chloride, $\mathrm{pH} 7.0$ ) and stored at $4^{\circ} \mathrm{C}$. Samples were postfixed in $1 \%$ osmium tetroxide for $2 \mathrm{~h}$ at $25^{\circ} \mathrm{C}$, dehydrated in a graded acetone series (30, $50,70,90$, and $100 \%$ ), and dried to the critical point in $\mathrm{CO}_{2}$ (Bal-tec CPD 030; Balzers). Root tissues containing nematodes were mounted on aluminum stubs, sputter coated with gold (Baltec SCD 050; Balzers), and examined with a SEM (LEO-435 VP) operating at $20 \mathrm{kV}$ with a working distance ranging from 10 to $30 \mathrm{~mm}$.

Race determination using North Carolina differential host test. Bioassays were carried out at the IPR. All LGM isolates were subjected to the North Carolina differential host test (NCDHT) (Hartman and Sasser 1985). The host set used in the test was 'Rutgers' tomato, 'NC95' tobacco, 'Deltapine 61' cotton (Gossypium hirsutum), 'Early California Wonder' pepper (Capsicum annuиm), 'Charleston Gray' watermelon (Citrullus vulgaris), and 'Florunner' peanut (Arachis hypogaea). Seedlings were planted in plastic pots $\left(500 \mathrm{~cm}^{3}\right)$ containing a sterile sandy soil.

Three seedlings of each differential host were inoculated with a suspension containing 2,000 nematodes (Nono-Womdim et al. 2002). After 60 days, roots were removed, washed, and stained with Phloxine
$\mathrm{B}$ (15 mg/liter for $20 \mathrm{~min}$ ), and the number of galls and egg masses were recorded, as follows: $0=$ no gall or egg mass and $1=1$ to $2,2=3$ to $10,3=11$ to $30,4=31$ to 100 , and $5=>100$ galls or egg masses. Differential hosts were rated as resistant ( $\leq 2$ egg masses) or susceptible ( $>2$ egg masses) (Hartman and Sasser 1985). The host test was repeated once.

Biometric characterization of Meloidogyne isolates. Biometric parameters from 10 second-stage juveniles (J2) and 10 males were measured for each isolate. Specimens were measured live under $\mathrm{LM}$ after relaxation at $5^{\circ} \mathrm{C}$ for $5 \mathrm{~min}$. The following parameters were measured: total body length, maximum body width, body width at anus level (J2), body width at stylet bulb level (males), body width at excretory pore level (males), stylet length, stylet bulb height, stylet bulb width, esophagus length (males), distance from stylet base to anterior region terminus ( $\mathrm{J} 2$ ), dorsal pharyngeal gland opening (DGO), distance from medium bulb to anterior region terminus, medium bulb valve length (J2), medium bulb valve width (J2), distance from excretory pore to anterior region terminus, hyaline tail terminus (J2), tail length, spicule length (males), and gubernaculum length (males). The de Man's ratios a, c, and c' along with stylet bulb height/stylet bulb width (males), length/distance from medium bulb to anterior region terminus, and distance from excretory pore to anterior region terminus $\times$ 100/length were calculated as well (Siddiqi 2000).

The biometric values were analyzed between species using parametric one-way analysis of variance (ANOVA) and means were compared by Tukey's honestly significant difference test $(P<0.05)$. This analysis allowed us to view differences between species based on each characteristic and, when present, to indicate which variables are capable of distinguishing one species from another. Additionally, the data set was submitted to principle component analysis (PCA) and later to hierarchical clustering analysis (Ward's method). This multivariate analysis allowed for the determination of the most robust discriminant trait and obtaining an overview of morphometric similarities at inter- and intraspecific levels. Both analyses were performed with the $\mathrm{R} 2.15$ program (R Development Core Team 2012).

\section{Results}

Morphological and biochemical analyses of Meloidogyne populations. The isozyme electrophoresis revealed eight Est phenotypes, six of them species specific (Fig. 1). There were $18(46.2 \%)$ samples with phenotypes of $M$. incognita (I1 and I2, Rm $=1.0$ and 1.1), $16(41 \%)$ of $M$. javanica $(\mathrm{J} 3, \mathrm{Rm}=1.0,1.3$, and 1.4), $10(25.6 \%)$ of $M$. enterolobii (VS1-S1, Rm $=0.75,0.85,1.0$ and $1.1), 2(5.1 \%)$ of $M$. arenaria $(\mathrm{A} 2, \mathrm{Rm}=1.25$ and 1.35$)$, and 1 (2.6\%) of $M$. inornata Lordello, 1956 (I3 $=\mathrm{Y3}, \mathrm{Rm}=0.90,1.25$, and 1.35). Two Est phenotypes were detected in 10 (25.6\%) samples. Unusual phenotypes were isolated for LGM $27(\mathrm{~F} 2, \mathrm{Rm}=0.75$, 0.90 and 0.95$)$ and LGM $38(\mathrm{~F} 3, \mathrm{Rm}=0.90,1.0$ and 1.1).

From the 483 specimens, we found perineal patterns for four species: M. javanica $(n=127)$, M. incognita $(n=141)$, M. enterolobii $(n=74)$, and $M$. arenaria $(n=37)$. Inconsistent patterns were found for M. incognita (13.5\%), small variations for $M$. javanica, and large variability for $M$. enterolobii $(39.3 \%)$ and $M$. arenaria $(27 \%)$. Specimens of $M$. javanica displayed small variations but always with the usual features, such as dorsal arch varying between low and moderately low and two conspicuous lateral incisures (Fig. 1A). For M. incognita, lateral lines often marked by bifurcations and high dorsal arch were observed (Fig. 1G). Although the majority of specimens of $M$. enterolobii showed perineal patterns similar to its description or to M. mayaguensis, we observed large variability, with $M$. arenaria or $M$. incognita-like types observed. Patterns varied between oval and rounded, with fine and spaced striae and moderately high dorsal arch (Fig. 1D). Some specimens had conspicuous lateral lines and others had one or two lateral wings.

The $M$. arenaria specimens had ovoid shape perineal patterns, with low dorsal arch, often dorsum-laterally compressed, forming small shoulders (Fig. 1C). Some specimens had one or two prominent lateral wings, as previously described (Carneiro et al. 2008b). In relation to LGM 27, patterns varied between round and oval, and there was absence of punctuations or lateral lines, with some 
specimens having one or two lateral wings (Fig. 1F). On the other hand, LGM 38 patterns were very close to M. incognita (Fig. 1E).

Sequencing of ITS1-rRNA gene. Amplification of the rRNA produced a unique fragment of about $429 \mathrm{bp}$ (354 to $442 \mathrm{bp}$ ), with the ITS-1 sequence varying from 202 and $215 \mathrm{bp}$. In general, the identification based on biochemical and morphological criteria was confirmed by the ITS 1 sequences. Sequence variation was in accordance with Meloidogyne spp.; that is, high for M. incognita (0 to $38.8 \%$ ) and low for $M$. javanica (0 to $1.6 \%$ ) and $M$. enterolobii (0 to $2.8 \%$ ). For $M$. incognita, sequences of LGM 01, 02, 06, 09, and 10 accounted for this heterogeneity. There was low polymorphism between the sequences of $M$. javanica, $M$. arenaria, and most sequences of $M$. incognita ( 0 to $1.1 \%$ ). The sequence of $M$. inornata differed from those of $M$. incognita (3.9 to 32.4\%), M. javanica (3.9 to $5.1 \%)$, M. enterolobii (9.8 to 11\%), LGM 27 (10.4\%), and LGM $38(3.9 \%)$. There was low divergence between sequences of M. enterolobii and JF309158.1 (1.6 to 2.8\%) and LGM 27 (0 to $0.5 \%$ ). Furthermore, there was a variable 12 nucleotide region found in the M. enterolobii sequences (data not shown).

Phylogenetic analysis allowed us to distinguish five clades, which are shown in Figure 2. The A+T content varied among clades, with values of $61.42 \%$ (clade i), $60 \%$ (clade ii), $61.9 \%$ (clade iii), $63.27 \%$ (clade iv), and $56.9 \%$ (clade v). Low divergence was observed in clades i $(0.2 \%)$ and iv (1.3\%) but high divergence was observed in clade v (10.9\%). Divergences varied considerably among clades (3.70 to $28.80 \%$ ).
Race determination using NCDHT. The NCDHT allowed us to categorize the 40 isolates as five Meloidogyne spp. (Table 2). We did not obtain an isolate from population LGM 05. Most of the results are in agreement with the specific delimitations obtained with other methods used in this study. Only five isolates (12.8\%) displayed unexpected host range: LGM 23, LGM 26, LGM 30, LGM 34, and LGM 10.1. Almost all $M$. incognita isolates were classified as race 2 (79\%) but LGM 36, LGM 39, and LGM 42 were classified as race 1 , because they parasitized watermelon, tomato and pepper, but not cotton, peanut or tobacco. About $60 \%$ of the $M$. enterolobii isolates were similar to $M$. incognita race 2 , reproducing on tomato, tobacco, watermelon and pepper, as noted in previous works (Brito et al. 2004; Rammah and Hirschmann 1988; Yang and Eisenback 1983). Some variants (LGM 23, LGM 26, LGM 30, and LGM 34) were unable to reproduce on pepper. Almost all $M$. javanica isolates showed a usual host range. Tomato, tobacco and watermelon were good hosts for them. Only LGM 10.1 parasitized pepper. This variant was also detected in another study (Ogbuji 1981).

Identification of the LGM 45 (M. inornata) isolate was confirmed, because its host range was identical to $M$. javanica, as in the $M$. inornata description (Carneiro et al. 2008a). The LGM 31 isolate was classified as $M$. arenaria race 2. Interestingly, LGM 27 had a host range similar to $M$. incognita race 2 and $M$. enterolobii. LGM 38 was similar to $M$. incognita race 1, not parasitizing tobacco, cotton, or peanut.

Biometric characterization of Meloidogyne isolates. Variations were observed for all species but most remained within the
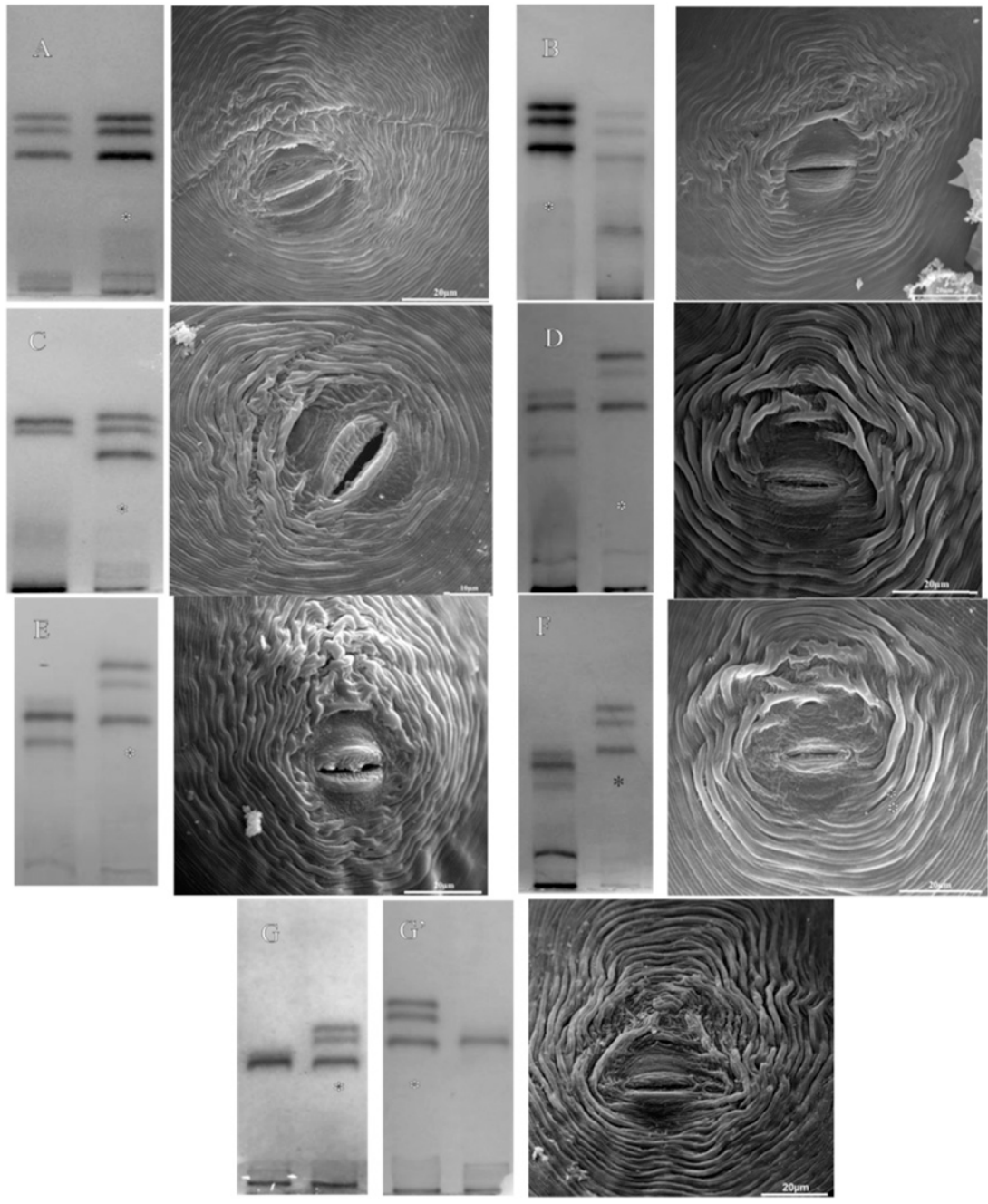

Fig. 1. Esterase phenotypes (right) and perineal patterns (left) for Meloidogyne spp. collected from tobacco fields in southern Brazil. Isolate of Meloidogyne javanica (J3) was used as reference. A, M. javanica (J3); B, M. inornata (I3); C, M. arenaria (A2); D, M. enterolobii (VS1-S1); E, LGM 38 (F3); F, LGM $27($ F2); and G and G', M. incognita (I1 and I2). 
limits reported in the original descriptions (data not shown). Significant differences were observed only on $M$. inornata males, a finding that could be attributed to the host plant, number of specimens, and measurement method (Brown and Tophan 1984).

For LGM 27, the obtained measurements were (i) for J2 specimens, length $=455.7 \mu \mathrm{m}( \pm 15.5)$, maximum body width $=16.7 \mu \mathrm{m}( \pm 1.0)$, body width at anus level $=11.4 \mu \mathrm{m}( \pm 0.5)$, stylet length $=10.5 \mu \mathrm{m}$ $( \pm 0.5)$, distance from stylet base to anterior region terminus $=$ $14.6 \mu \mathrm{m}( \pm 0.5)$, stylet bulb height $=1.6 \mu \mathrm{m}( \pm 0.2)$, diameter of the bulb of the stylet $=2.5 \mu \mathrm{m}( \pm 0.0), \mathrm{DGO}=3.3 \mu \mathrm{m}( \pm 0.3)$, distance from medium bulb to anterior region terminus $=$ $50.2 \mu \mathrm{m}( \pm 2.0)$, medium bulb valve length $=4.5 \mu \mathrm{m}( \pm 0.0)$, medium bulb valve width $=3.0 \mu \mathrm{m}( \pm 0.0)$, distance from excretory pore to anterior region terminus $=90.2 \mu \mathrm{m}( \pm 2.1)$, tail length $=$ $51.5 \mu \mathrm{m}( \pm 2.8)$, hyaline tail terminus $=12.2 \mu \mathrm{m}( \pm 2.1), \mathrm{a}=$
$27.5( \pm 2.1), c=8.9( \pm 0.4), c^{\prime}=4.5( \pm 0.2)$, length/distance from medium bulb to anterior region terminus $=9.1( \pm 0.5)$, and distance from excretory pore to anterior region terminus $\times 100 /$ length $=19.8$ ( \pm 0.8$)$; and (ii) for males, length $=2,052.1 \mu \mathrm{m}( \pm 124.6)$, maximum body width $=52.9 \mu \mathrm{m}( \pm 4.5)$, stylet bulb width $=20.5 \mu \mathrm{m}( \pm 0.7)$, diameter at the level of the excretory pore $=25.9 \mu \mathrm{m}( \pm 0.7)$, esophagus length $=99.8 \mu \mathrm{m}( \pm 4.9)$, stylet length $=23.1 \mu \mathrm{m}( \pm 0.7)$, stylet bulb height $=3.5 \mu \mathrm{m}( \pm 0.4)$, stylet bulb width $=5.6 \mu \mathrm{m}( \pm 0.4)$, DGO $=$ $4.1 \mu \mathrm{m}( \pm 0.4)$, distance from medium bulb to anterior region terminus $=96.5 \mu \mathrm{m}( \pm 6.1)$, distance from excretory pore to anterior region terminus $=153.2 \mu \mathrm{m}( \pm 7.0)$, tail length $=16.3 \mu \mathrm{m}( \pm 1.4)$, spicule length $=25.3 \mu \mathrm{m}( \pm 0.7)$, gubernaculum length $=8.6 \mu \mathrm{m}( \pm 1.1)$, a $=38.9( \pm 2.5), \mathrm{c}=126.4( \pm 8.1)$, length/distance from medium bulb to anterior region terminus $=21.3 \mu \mathrm{m}( \pm 1.9)$, stylet bulb height/stylet bulb width $=1.6( \pm 0.1)$, and distance from excretory pore to anterior region terminus $\times 100 /$ length $=7.5( \pm 0.5)$.

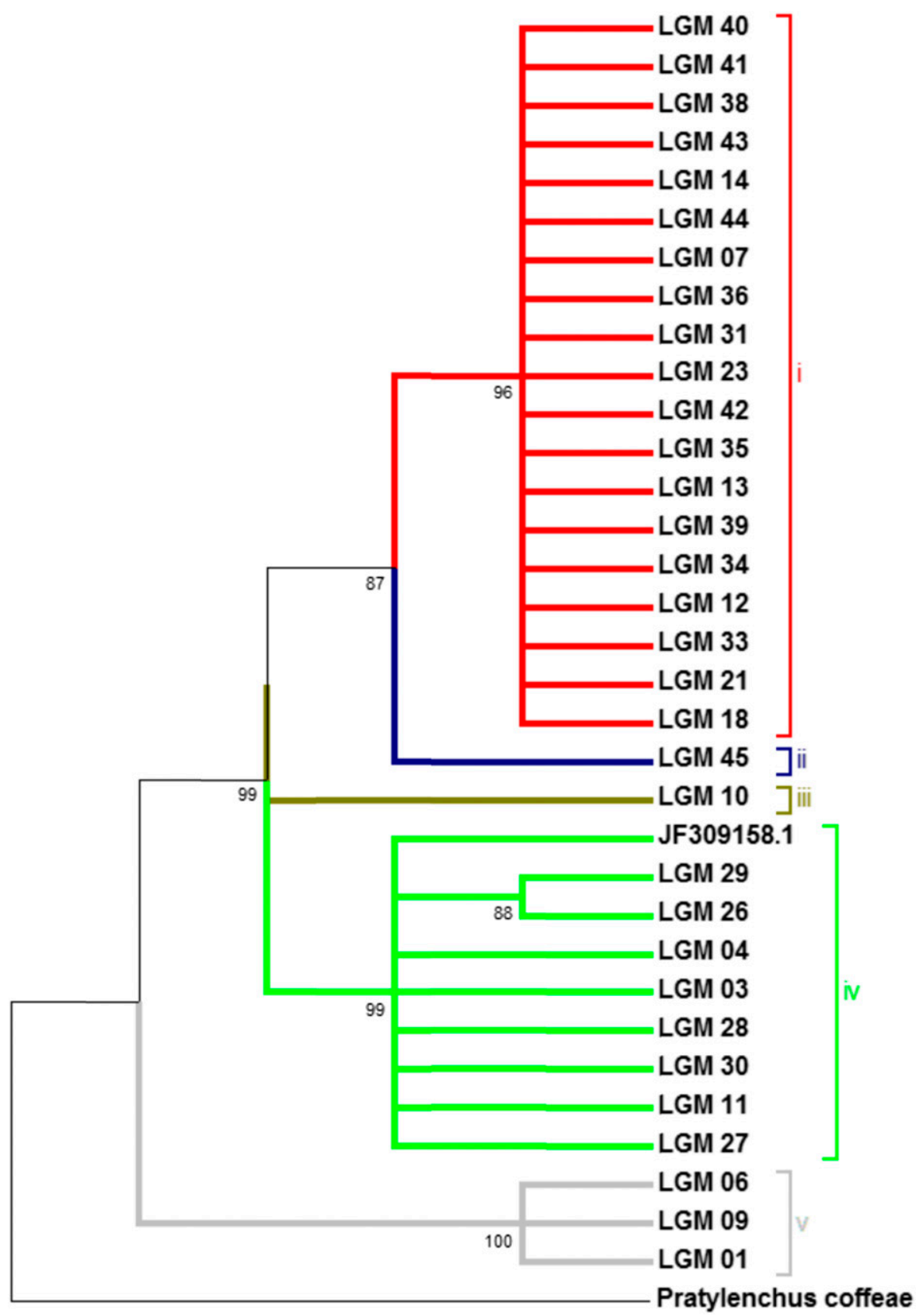

Fig. 2. Phylogenetic tree (unweighted pair group method with arithmetic means) resulting from the alignment of the internal transcribed spacer 1 sequences of several populations of Meloidogyne spp. from tobacco fields in Brazil. Bootstrap support more than $70 \%$ for appropriate clade. Phylogenetic analysis distinguished five clades: (i) Meloidogyne incognita, M. javanica, M. arenaria, and LGM 38 populations; (ii) LGM 45; (iii) LGM10; (iv) M. enterolobii and LGM 27 populations; and (v) M. incognita populations. 
For LGM 38, the measurements were (i) for J2 specimens, length $=$ $416.0 \mu \mathrm{m}( \pm 27.4)$, maximum body width $=15.9 \mu \mathrm{m}( \pm 1.7)$, body width at anus level $=10.5 \mu \mathrm{m}( \pm 0.7)$, stylet length $=10.7 \mu \mathrm{m}$ $( \pm 0.7)$, distance from stylet base to anterior region terminus $=$ $15.1 \mu \mathrm{m}( \pm 0.3)$, stylet bulb height $=1.5 \mu \mathrm{m}( \pm 0.0)$, diameter of the bulb of the stylet $=2.5 \mu \mathrm{m}( \pm 0.0)$, DGO $=3.1 \mu \mathrm{m}( \pm 0.2)$, distance from medium bulb to anterior region terminus $=52.1 \mu \mathrm{m}$ $( \pm 3.0)$, medium bulb valve length $=4.1 \mu \mathrm{m}( \pm 0.3)$, medium bulb valve width $=3.2 \mu \mathrm{m}( \pm 0.3)$, distance from excretory pore to anterior region terminus $=86.7 \mu \mathrm{m}( \pm 7.0)$, tail length $=51.5 \mu \mathrm{m}( \pm 3.4)$, hyaline tail terminus $=11.4 \mu \mathrm{m}( \pm 1.3), \mathrm{a}=26.2( \pm 1.4), \mathrm{c}=8.1( \pm 0.4)$, $\mathrm{c}^{\prime}=4.9( \pm 0.3)$, length/distance from medium bulb to anterior region terminus $=8.0( \pm 0.7)$, and distance from excretory pore to anterior region terminus $\times 100 /$ length $=20.9( \pm 2.3)$; and (ii) for males, length $=1,519.5 \mu \mathrm{m}( \pm 50.0)$, maximum body width $=42.1 \mu \mathrm{m}$ $( \pm 2.5)$, stylet bulb width $=18.8 \mu \mathrm{m}( \pm 0.8)$, diameter at the level of the excretory pore $=29.0 \mu \mathrm{m}( \pm 0.8)$, esophagus length $=$ $101.5 \mu \mathrm{m}( \pm 3.0)$, stylet length $=24.7 \mu \mathrm{m}( \pm 0.7)$, stylet bulb height $=$ $4.4 \mu \mathrm{m}( \pm 0.4)$, stylet bulb width $=6.3 \mu \mathrm{m}( \pm 0.4), \mathrm{DGO}=4.0 \mu \mathrm{m}$ $( \pm 0.4)$, distance from medium bulb to anterior region terminus $=$ $115.5 \mu \mathrm{m}( \pm 7.2)$, distance from excretory pore to anterior region terminus $=153.3 \mu \mathrm{m}( \pm 7.2)$, tail length $=24.8 \mu \mathrm{m}( \pm 0.8)$, spicule length $=29.0 \mu \mathrm{m}( \pm 0.8)$, gubernaculum length $=9.3 \mu \mathrm{m}( \pm 0.8)$, a $=37.9( \pm 1.7), \mathrm{c}=64.2( \pm 2.9)$, length/distance from medium bulb to anterior region terminus $=13.8( \pm 0.9)$, stylet bulb height/stylet bulb width $=1.4( \pm 0.1)$, and distance from excretory pore to anterior region terminus $\times 100 /$ length $=9.6( \pm 0.5)$.

The ANOVA revealed significant differences between species for all variables $(P<0.05)$. Nevertheless, a small number of variables were useful to differentiate Meloidogyne spp., such as body width at anus level and hyaline tail terminus (J2) for $M$. enterolobii; tail length and distance from excretory pore to anterior region terminus $\times 100 /$ length $(\mathrm{J} 2)$ for $M$. arenaria; c (J2) for M. inornata; and DGO, a, distance from excretory pore to anterior region terminus $\times 100 /$ length, and length/distance from medium bulb to anterior region terminus (males) for $M$. javanica. The LGM 27 differed from $M$. enterolobii in only one variable (stylet bulb height/stylet bulb width) for males.

Low intraspecific variability was observed by PCA analysis from J2 measurements, with high correspondence (computable general equilibrium, CGE) between phenetic clusters and species characterized using other methods in this study but with slight interspecific overlap. The percentage of variance explained (inertia) by the first two principle components (PC) was 52.6\%. PC1 was positive for

Table 2. Codes of isolates and host range results for Meloidogyne spp. collected from tobacco fields in Brazil planted with cultivars containing $R k$ resistance

\begin{tabular}{|c|c|c|c|c|c|c|c|}
\hline \multirow[b]{2}{*}{ Species } & \multicolumn{7}{|c|}{ Differential hosts $^{a}$} \\
\hline & Codes & Tobacco & Tomato & Watermelon & Peanut & Pepper & Cotton \\
\hline \multirow[t]{14}{*}{ Meloidogyne incognita } & LGM 01 & $4.67 \pm 0.52$ & $5.0 \pm 0$ & $5.0 \pm 0$ & $0 \pm 0$ & $3.83 \pm 0.41$ & $0 \pm 0$ \\
\hline & LGM 02 & $4.5 \pm 0.55$ & $5.0 \pm 0$ & $5.0 \pm 0$ & $0 \pm 0$ & $3.83 \pm 0.41$ & $0 \pm 0$ \\
\hline & LGM 06 & $4.5 \pm 0.55$ & $5.0 \pm 0$ & $5.0 \pm 0$ & $0 \pm 0$ & $2.17 \pm 0.75$ & $0 \pm 0$ \\
\hline & LGM 07.2 & $4.0 \pm 0.63$ & $3.83 \pm 0.41$ & $4.8 \pm 0.45$ & $0 \pm 0$ & $2.83 \pm 0.41$ & $0 \pm 0$ \\
\hline & LGM 09 & $4.67 \pm 0.52$ & $4.83 \pm 0.41$ & $4.4 \pm 0.89$ & $0 \pm 0$ & $4.33 \pm 0.52$ & $0 \pm 0$ \\
\hline & LGM 10.2 & $4.83 \pm 0.41$ & $4.5 \pm 0.55$ & $4.4 \pm 0.55$ & $0 \pm 0$ & $2.83 \pm 0.75$ & $0 \pm 0$ \\
\hline & LGM 14 & $4.83 \pm 0.41$ & $4.0 \pm 0.63$ & $4.0 \pm 0$ & $0 \pm 0$ & $2.5 \pm 0.84$ & $0 \pm 0$ \\
\hline & LGM 16 & $3.67 \pm 1.37$ & $5.0 \pm 0$ & $5.0 \pm 0$ & $0 \pm 0$ & $3.67 \pm 0.81$ & $0 \pm 0$ \\
\hline & LGM 35 & $4.6 \pm 0.55$ & $5.0 \pm 0$ & $5.0 \pm 0$ & $0 \pm 0$ & $3.4 \pm 0.55$ & $0 \pm 0$ \\
\hline & LGM 36 & $0.17 \pm 0.41$ & $5.0 \pm 0$ & $4.4 \pm 0.55$ & $0 \pm 0$ & $2.5 \pm 0.55$ & $0 \pm 0$ \\
\hline & LGM 39 & $0 \pm 0$ & $5.0 \pm 0$ & $5.0 \pm 0$ & $0 \pm 0$ & $4.0 \pm 0$ & $0 \pm 0$ \\
\hline & LGM 40 & $3.17 \pm 0.75$ & $5.0 \pm 0$ & $4.5 \pm 0.55$ & $0 \pm 0$ & $3.33 \pm 0.52$ & $0 \pm 0$ \\
\hline & LGM 41 & $4.33 \pm 0.82$ & $4.83 \pm 0.41$ & $5.0 \pm 0$ & $0 \pm 0$ & $4.17 \pm 0.41$ & $0 \pm 0$ \\
\hline & LGM 42 & $0.33 \pm 0.82$ & $5 \pm 0$ & $4.67 \pm 0.52$ & $0 \pm 0$ & $1.8 \pm 1.79$ & $0 \pm 0$ \\
\hline \multirow[t]{12}{*}{ M. javanica } & LGM 07.1 & $4.5 \pm 0.55$ & $5.0 \pm 0$ & $3.4 \pm 0.55$ & $0 \pm 0$ & $0 \pm 0$ & $0 \pm 0$ \\
\hline & LGM 08 & $4.67 \pm 0.52$ & $4.4 \pm 0.55$ & $4.6 \pm 0.55$ & $0 \pm 0$ & $0.33 \pm 0.82$ & $0 \pm 0$ \\
\hline & LGM 10.1 & $5 \pm 0$ & $5 \pm 0$ & $5 \pm 0$ & $0 \pm 0$ & $4.2 \pm 0.84$ & $0 \pm 0$ \\
\hline & LGM 12 & $3.67 \pm 0.52$ & $3.33 \pm 0.52$ & $4.6 \pm 0.55$ & $0 \pm 0$ & $0 \pm 0$ & $0 \pm 0$ \\
\hline & LGM 13 & $5.0 \pm 0$ & $5.0 \pm 0$ & $5.0 \pm 0$ & $0 \pm 0$ & $0 \pm 0$ & $0 \pm 0$ \\
\hline & LGM 17 & $4.33 \pm 0.52$ & $4.17 \pm 0.75$ & $5.0 \pm 0$ & $0 \pm 0$ & $0 \pm 0$ & $0 \pm 0$ \\
\hline & LGM 18 & $4.5 \pm 0.55$ & $4.83 \pm 0.41$ & $5.0 \pm 0$ & $0 \pm 0$ & $0.4 \pm 0.89$ & $0 \pm 0$ \\
\hline & LGM 21 & $4.67 \pm 0.52$ & $5.0 \pm 0$ & $4.6 \pm 0.55$ & $0 \pm 0$ & $0.17 \pm 0.41$ & $0 \pm 0$ \\
\hline & LGM 33 & $4.67 \pm 0.52$ & $4.83 \pm 0.41$ & $4.83 \pm 0.41$ & $0 \pm 0$ & $0.5 \pm 0.84$ & $0 \pm 0$ \\
\hline & LGM 37 & $4.33 \pm 0.52$ & $5 \pm 0$ & $5 \pm 0$ & $0 \pm 0$ & $0 \pm 0$ & $0 \pm 0$ \\
\hline & LGM 43 & $5.0 \pm 0$ & $5.0 \pm 0$ & $5.0 \pm 0$ & $0 \pm 0$ & $0 \pm 0$ & $0 \pm 0$ \\
\hline & LGM 44 & $4.67 \pm 0.52$ & $4.67 \pm 0.52$ & $4.2 \pm 0.84$ & $0 \pm 0$ & $0.33 \pm 0.51$ & $0 \pm 0$ \\
\hline \multirow[t]{10}{*}{ M. enterolobii } & LGM 03 & $5.0 \pm 0$ & $5.0 \pm 0$ & $4.0 \pm 0.89$ & $0 \pm 0$ & $3.67 \pm 0.52$ & $0.33 \pm 0.52$ \\
\hline & LGM 04 & $4.83 \pm 0.41$ & $4.83 \pm 0.41$ & $4.67 \pm 0.52$ & $0 \pm 0$ & $3.5 \pm 0.55$ & $0 \pm 0$ \\
\hline & LGM 11 & $4.2 \pm 0.40$ & $4.8 \pm 0.40$ & $5.0 \pm 0$ & $0 \pm 0$ & $3.2 \pm 0.40$ & $0 \pm 0$ \\
\hline & LGM 23 & $3.0 \pm 0$ & $3.5 \pm 0.55$ & $5.0 \pm 0$ & $0 \pm 0$ & $0.17 \pm 0.41$ & $0 \pm 0$ \\
\hline & LGM 26 & $3.17 \pm 0.41$ & $3.5 \pm 0.55$ & $4.4 \pm 0.55$ & $0 \pm 0$ & $0.17 \pm 0.41$ & $0 \pm 0$ \\
\hline & LGM 28 & $3.83 \pm 0.75$ & $5.0 \pm 0$ & $4.83 \pm 0.41$ & $0 \pm 0$ & $3.4 \pm 0.55$ & $0 \pm 0$ \\
\hline & LGM 29.1 & $4.83 \pm 0.41$ & $5.0 \pm 0$ & $4.0 \pm 1.22$ & $0 \pm 0$ & $3.83 \pm 0.41$ & $0.17 \pm 0.41$ \\
\hline & LGM 30 & $4.67 \pm 0.52$ & $3.67 \pm 0.52$ & $4.4 \pm 0.55$ & $0 \pm 0$ & $0 \pm 0$ & $0 \pm 0$ \\
\hline & LGM 32 & $4.5 \pm 0.83$ & $4.7 \pm 0.52$ & $3.6 \pm 0.55$ & $0 \pm 0$ & $4.2 \pm 0.75$ & $0 \pm 0$ \\
\hline & LGM 34 & $4.67 \pm 0.52$ & $5.0 \pm 0$ & $5.0 \pm 0$ & $0 \pm 0$ & $1.5 \pm 0.54$ & $0 \pm 0$ \\
\hline M. arenaria & LGM 31 & $4.8 \pm 0.40$ & $4.7 \pm 0.52$ & $4.4 \pm 0.55$ & $0 \pm 0$ & $0.83 \pm 0.98$ & $0 \pm 0$ \\
\hline M. inornata & LGM 45 & $3.5 \pm 0.55$ & $5.0 \pm 0$ & $4.67 \pm 0.52$ & $0 \pm 0$ & $0 \pm 0$ & $0 \pm 0$ \\
\hline Meloidogyne sp. 1 & LGM 27 & $4.17 \pm 0.41$ & $5.0 \pm 0$ & $4.0 \pm 0$ & $0 \pm 0$ & $2.5 \pm 1.38$ & $0 \pm 0$ \\
\hline Meloidogyne sp. 2 & LGM 38 & $1 \pm 0.60$ & $5.0 \pm 0$ & $5.0 \pm 0$ & $0 \pm 0$ & $3.8 \pm 0.40$ & $0 \pm 0$ \\
\hline
\end{tabular}

${ }^{a}$ Gall rating index according to the scale $0=$ no galls and $1=1$ to $2,2=3$ to $10,3=11$ to $30,4=31$ to 100 , and $5=>100$ galls. Differential hosts were rated as resistant $(\leq 2)$ or susceptible $(>2)$ (Hartman and Sasser 1985). 
10 traits and closely correlated with maximum body width (0.92) and body width at anus level (0.95); PC2 was positive for 15 traits and closely correlated with length (0.93). From this analysis, we could observe three clusters (Fig. 3): (i) all M. incognita isolates (100\% of CGE), LGM 27, LGM 38, LGM 32 (M. enterolobii), and $M$. javanica (LGM 43 and LGM 44); (ii) the majority (70\% of
CGE) of M. enterolobii isolates (LGM 34, LGM 04, LGM 28, LGM 29.1, LGM 30, LGM 23, and LGM 26); and (iii) the majority (85\% of CGE) of $M$. javanica isolates (LGM 07.1, LGM 08, LGM 10.1, LGM 12, LGM 13, LGM 17, LGM 18, LGM 21, LGM 29.2, LGM 33, and LGM 37), M. enterolobii (LGM 03 and LGM 11), M. arenaria, and $M$. inornata.
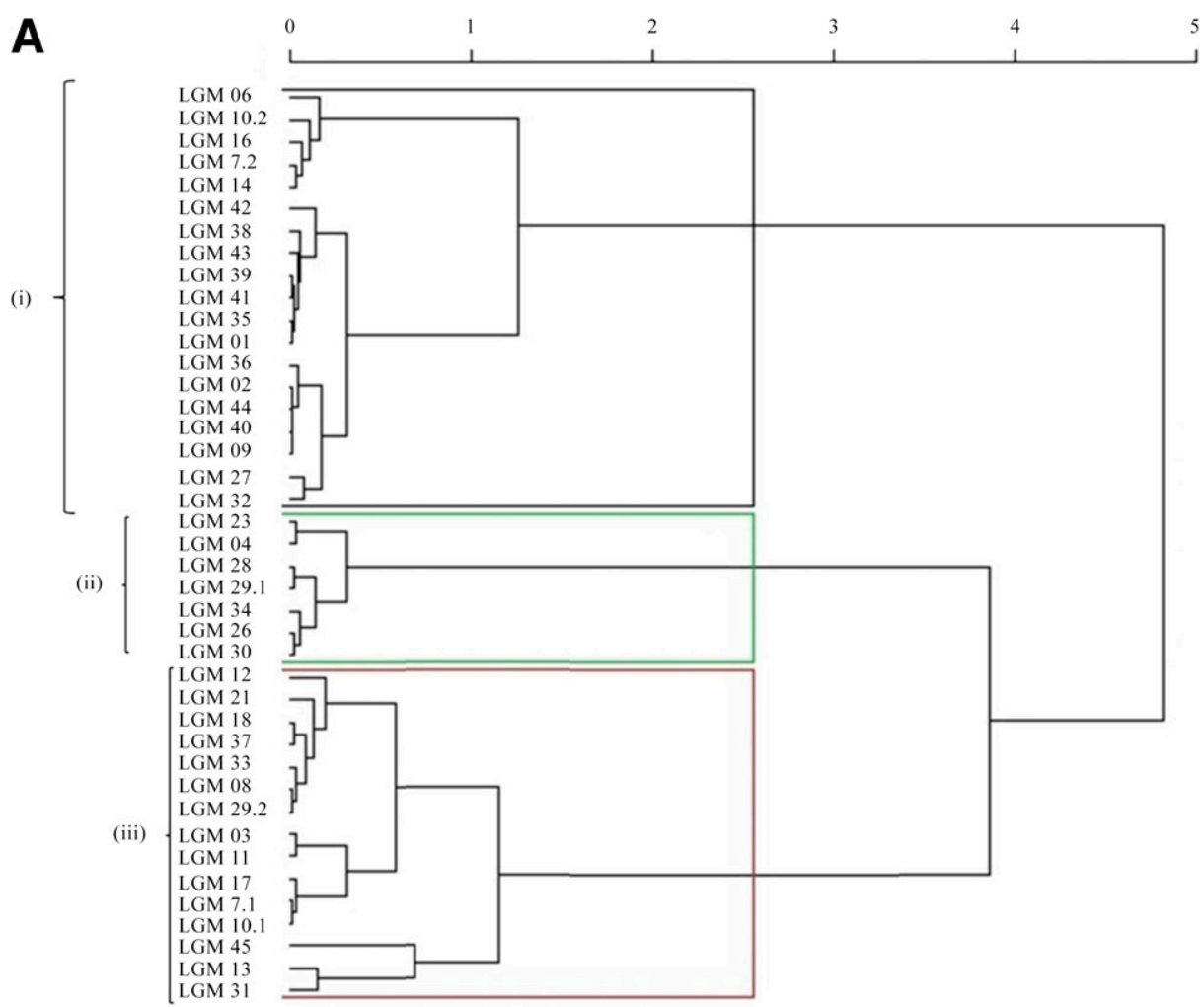

B
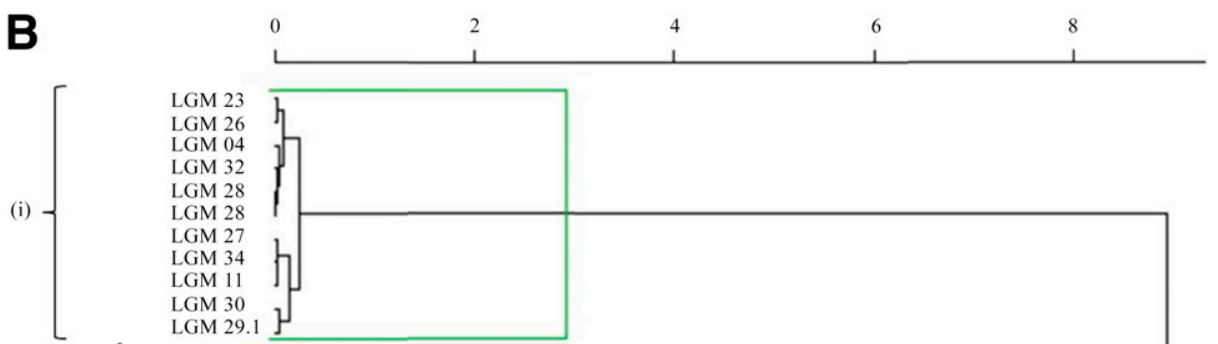

(ii)

LGM 23

LGM 26

LGM 04

LGM 32

LGM 28

LGM 28

LGM 27

LGM 34

LGM 30
LGM 29.1

LGM 37

LGM 07.1

LGM 33

LGM 08

LGM 21

LGM 18

LGM 17

LGM 10.1

LGM 12

LGM 29.2
LGM 38

LGM 38
LGM 31

LGM 45

LGM 36

LGM 41

LGM 43

LGM 44

LGM 16
LGM 35

(iii)

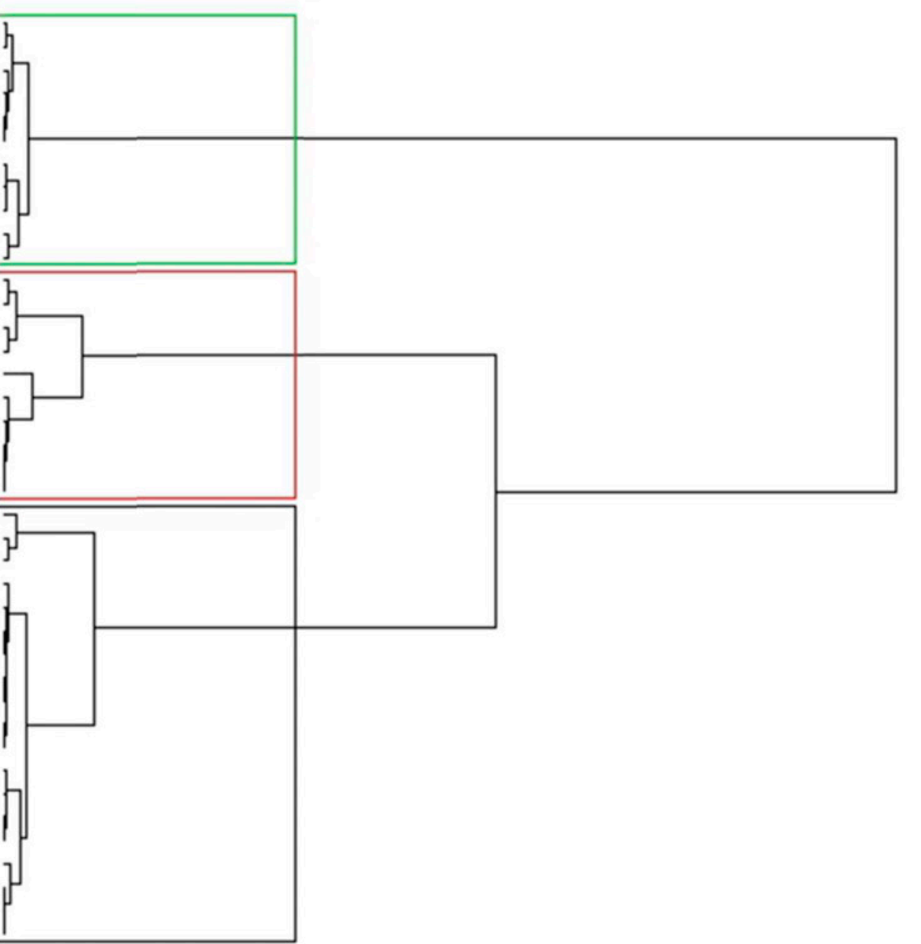

Fig. 3. Dendrograms obtained from morphometric data of $\mathbf{A}$, second-stage juveniles and $\mathbf{B}$, males of Meloidogyne spp. from tobacco fields in Brazil subjected to principle components analysis. 
The findings for the adult male specimens were consistent with those for $\mathrm{J} 2$ but with higher CGE indices. The inertia explained by the two first PC was $76.7 \%$. PC1 was positive for 10 traits and closely correlated with length (0.97), maximum body width (0.97), and c (0.98); PC2 was positive for 9 traits and closely correlated with diameter of the bulb of the stylet (0.93). We could observe three clusters (Fig. 3): (i) all M. enterolobii isolates (100\% of CGE) and LGM 27; (ii) the majority (92\% of CGE) of $M$. javanica isolates (LGM 07.1, LGM 08, LGM 10.1, LGM 12, LGM 17, LGM 18, LGM 21, LGM 29.2, LGM 33, and LGM 37); and (iii) all $M$. incognita isolates (100\% of CGE), M. javanica (LGM 43 and LGM 44), M. arenaria, M. inornata, and LGM 38.

\section{Discussion}

Our results demonstrated that disease caused by Meloidogyne spp. on $R k$ tobacco varieties occurs due to virulent $M$. incognita populations and the presence of other Meloidogyne spp., mainly M. javanica and M. enterolobii. Because there is no information about the national scenario before the introduction of $R k$ tobacco varieties, the hypothesis of directional selection favoring virulent populations is probable but not conclusive.

Perineal patterns showed limited power for identification of Meloidogyne spp., because unusual specimens occur commonly in monospecific populations and sibling species can coexist in the same sample. These situations are difficult even for expert taxonomists, resulting in misdiagnosis (Cofcewicz et al. 2004). High intraspecific variability in perineal patterns from populations of $M$. enterolobii was found in this study as well as in other studies (Almeida et al. 2008; Brito et al. 2008). Moreover, a considerable number of species exhibited perineal patterns similar to those of $M$. incognita (Handoo et al. 2005; Moens et al. 2010). Therefore, the adoption of less-subjective approaches to identify Meloidogyne spp. such as Est electrophoresis is indispensable (Brito et al. 2004; Carneiro et al. 2000).

The presence of $M$. incognita populations in two distinct clades corroborates previous studies (Hugall et al. 1999), in which the complexity of ribosomal genes in apomictic tropical species was documented. Disparities between morphological data and ITS-1-RNA sequence data have been documented not only for Meloidogyne spp. but also for all nematodes (Mes and Cornelissen 2004). This incongruence restricts the diagnostic value of these sequences (Handoo et al. 2005). There are likely morphological or biochemical species indistinguishable from $M$. incognita sensu stricto, which could have evolved in a convergent manner. For instance, various Meloidogyne spp. have been described from M. incognita similar isolates (Carneiro et al. 2008a; Handoo et al. 2005). In relation to $M$. enterolobii, the polymorphism between sequences from $M$. enterolobii and others is a promising finding because it will enable the development of specific primers. The observation of a cluster composed only of LGM 45 supports its unique taxonomic status.

Biometrically, high CGE ratifies the taxonomic value of quantitative variables, as long as these variables are submitted to the proper multivariate statistical analyses. Analyses of these combinations allowed a better understanding of the morphometric relationships between Meloidogyne populations. On the other hand, univariate analyses demonstrated a low capacity to discriminate Meloidogyne spp.

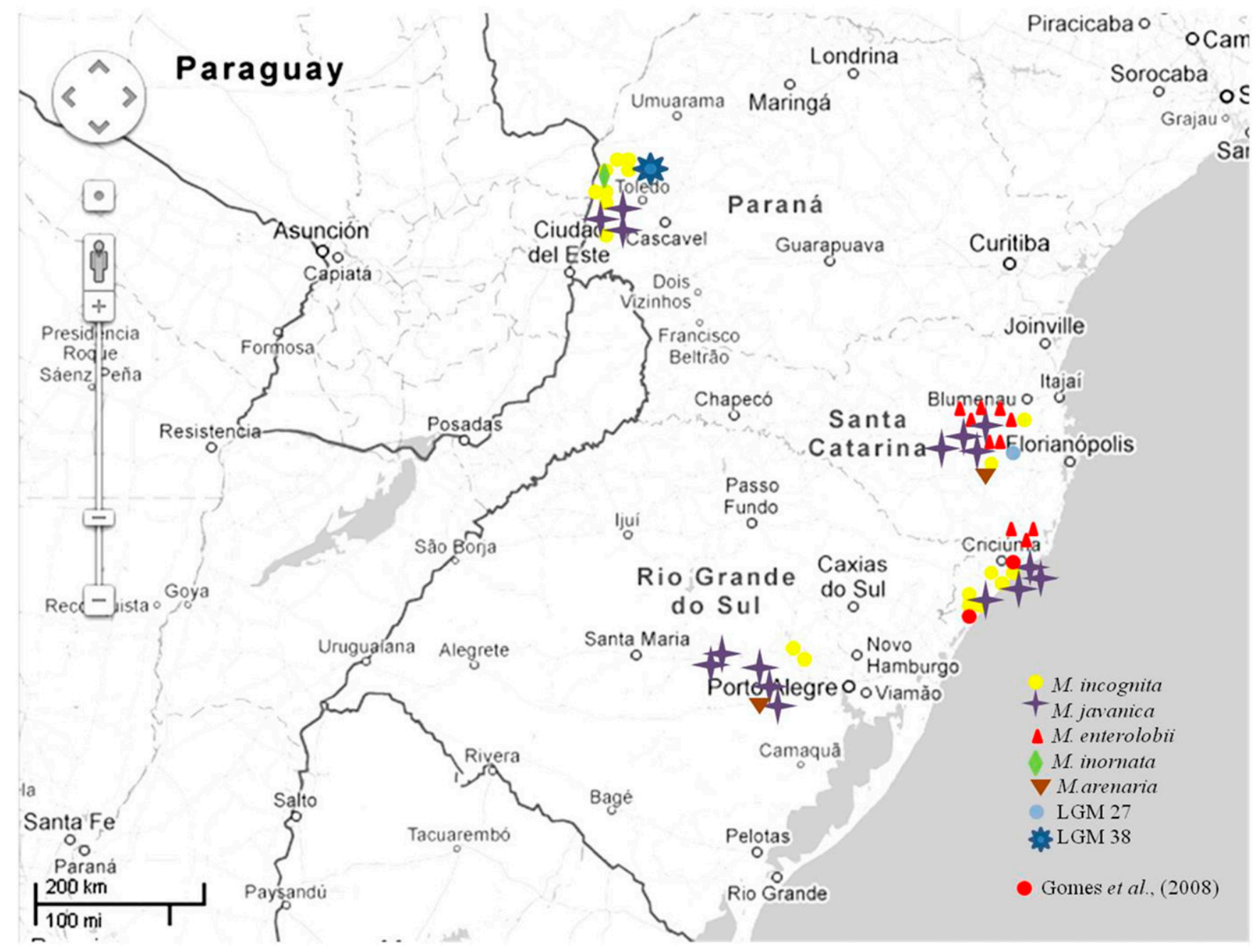

Fig. 4. Distribution of Meloidogyne spp. identified in tobacco fields in southern Brazil. Symbols represent the species. 
Unfortunately, the taxonomic status of LGM 27 and LGM 38 could not be resolved here. LGM 38 could be a unique biochemical variant (new phenotype) from $M$. incognita, because there was amplification of species-specific fragments by SCAR markers. However, this hypothesis should be taken with caution due to the limitations of these markers. LGM 38 is perhaps only a closely related taxon. The proximity between LGM 27 and M. enterolobii was very evident. Morphological and additional molecular studies will be necessary to solve the taxonomic status of both isolates.

The predominance of virulent genotypes under high-pressure selection has already been observed in the United States, Australia, and Brazil (Rich and Garcia 1985; Stanton et al. 1992; Zem et al. 1985). In the United States and Australia, this predominance was attributed to directional selection. The unexpected occurrence of avirulent populations (LGM 36, LGM 38, LGM 39, and LGM 42) to tobacco NC95 $(R k)$, as observed with the NCHT, parasitizing and causing disease on $R k$ cultivars, is probably explained by the occurrence of high temperatures $\left(30\right.$ to $35^{\circ} \mathrm{C}$ ) at which the $R k$ gene are rendered ineffective (Ogbuji 1981). In relation to M. enterolobii, variations in virulence have been observed worldwide, and our data further support the existence of host races of this parasite (Brito et al. 2004).

The present results showed that the range of Meloidogyne spp. that occur in tobacco crops in Brazil was higher than expected and included $M$. incognita, $M$. javanica, M. enterolobii, M. arenaria, and $M$. inornata. This diversity of species could be due to the more judicious identification but also to alterations in species composition as a result of intensive and prolonged use of the $R k$ gene. Indeed, the second hypothesis is corroborated by the NCHT results, in which prevalence of $M$. incognita race 2 was observed. Despite the predominance of $M$. incognita, its distribution was lower than that of $M$. javanica and M. enterolobii.

Contrary to a previous report (Zem et al. 1985), in our study, M. arenaria had a lower percentage of occurrence (5.1\%). M. enterolobii, in turn, was the third most prevalent species $(25.6 \%)$. This finding, combined with previous reports (Gomes et al. 2008), shows the importance of M. enterolobii as a tobacco pathogen due to not only its high incidence but also its distribution, especially in Santa Catarina (Fig. 4). However, questions about its recent detection need to be answered. Was M. enterolobii introduced and spread during this lapse of time? What is the cause of its rising incidence? Is $M$. enterolobii an indigenous species? Was M. enterolobii wrongly identified, probably due to the inherent difficulty of the methods used at that time? Based on the premise that $M$. enterolobii exhibits high morphological variability and that, in the past, the Meloidogyne spp. identification was performed almost exclusively by observation of morphology, the hypothesis that $M$. enterolobii has been misidentified as $M$. arenaria or $M$. incognita is plausible. Indeed, due to the adoption of nonsubjective criteria such as biochemical markers, the number of reports of $M$. enterolobii has increased worldwide (Almeida et al. 2008; Brito et al. 2008). In addition, $M$. enterolobii was detected parasitizing Senefeldera multiflora in an Atlantic Forest area in Rio de Janeiro state, demonstrating the indigenous presence of this nematode in Brazil and refuting the hypothesis of introduction (Lima et al. 2005). Moreover, the distribution of $M$. enterolobii overlaps the areas of the original Atlantic Forest biome. Corroborating this theory is the fact that the E180 population, from which M. mayaguensis ( $=$ M. enterolobii) was described, was first identified as M. arenaria (Rammah and Hirschmann 1988).

To our knowledge, this is the first report of $M$. inornata parasitizing tobacco in the southern region of Brazil. Previously, this species, first described in the 1950s, was observed on tobacco in the state of São Paulo (Figueiredo 1958). We believe that this nematode has often been identified as $M$. incognita due to the low use of biochemical markers and to the failure to observe morphological parameters of males and juveniles. The identification of M. inornata in our study was possible only by Est phenotypes, because its perineal pattern is very similar to $M$. incognita (Carneiro et al. 2008a).

Our findings have great practical importance, because they imply a considerable alteration in Meloidogyne management. Plant species used for rotation or succession schemes are limited for M. enterolobii when compared with the options available for $M$. javanica and $M$. incognita. There are few recognized nonhosts of $M$. enterolobii (Brito et al. 2007; Moens et al. 2010). This line of reasoning is also applied to management with plant resistance. Although there are no cultivars with high resistance to virulent biotypes of $M$. incognita (races 2 and 4), M. arenaria (race 2), and M. javanica, resistance sources are known in wild Nicotiana spp. (Davis et al. 1988; Di Vito et al. 1998; Johnson et al. 2005). However, there is no information on plant resistance for M. enterolobii. This is important because $M$. enterolobii can parasitize even cultivars carrying resistance genes, which generally confer resistance to $M$. incognita, M. javanica, and M. arenaria (Brito et al. 2007; Cetintas et al. 2007). Another question is the nonexistence of economic threshold levels for $M$. enterolobii on tobacco plants. It is known that, on some crops, M. enterolobii exhibits higher multiplication rates and pathogenicity levels than M. incognita (Cetintas et al. 2007); the implications of this on tobacco are unknown. In summary, it is necessary to conduct studies in the future that will support the integration of several management strategies targeting Meloidogyne spp. on tobacco crops.

\section{Acknowledgments}

The National Council for Scientific and Technological Development provided an academic grant to J. V. de Araújo Filho. We thank R. M. D. G. Carneiro (Embrapa/Cenargem) and R. D'arc de Lima Oliveira (Universidade Federal de Viçosa-UFV) for their valuable help in this work

\section{Literature Cited}

ABIFUMO. 2013. Associação Brasileira da Indústria do Tabaco. Online publication. http://www.abifumo.org.br/produ.htm

Almeida, E. J., Soares, P. L. M., Silva, A. R., and Santos, J. M. 2008. Novos registros de Meloidogyne mayaguensis no Brasil e estudo morfológico comparativo com M. incognita. Nematol. Bras. 32:236-241.

Brito, J. A., Kaur, R., Cetintas, R., Stanley, J. D., Mendes, M. L., McAvoy, E. J., Powers, T. O., and Dickson, D. W. 2008. Identification and isozymes characterization of Meloidogyne spp. infecting horticultural and agronomic crops, and weed plant in Florida. Nematology 10:757-766.

Brito, J. A., Powers, T. O., Mullin, P. G., Inserra, R. N., and Dickson, D. W. 2004 Morphological and molecular characterization of Meloidogyne mayaguensis isolates from Florida. J. Nematol. 36:232-240.

Brito, J. A., Stanley, J. D., Kaur, R., Cetintas, R., Di Vito, M., Thies, J. A., and Dickson, D. W. 2007. Effects of the Mi-1, N, Tabasco genes on infection and reproduction of $M$. mayaguensis on tomato and pepper genotypes. J. Nematol. 39:327-332.

Brown, D. J. F., and Tophan, P. B. 1984. A comparison of the reported variation in the morphometrics of Xiphinema diversicaudatum (Nematoda: Dorylaimida) and the effect of preparing specimens for examination by optical microscopy. Nematol. Mediterr. 12:169-186.

Carneiro, R. M. D. G., Almeida, M. R. A., and Quénéhervé, P. 2000. Enzyme phenotypes of Meloidogyne spp. populations. Nematology 2:645-654.

Carneiro, R. M. D. G., Mendes, L. M., Almeida, M. R. A., Santos, M. F. A., Gomes, A. C. M. M., and Karssen, G. 2008a. Additional Information on Meloidogyne inornata Lordello, 1956 (Tylenchida: Meloidogynidae) and its characterization as valid species. Nematology 10:123-136.

Carneiro, R. M. D. G., Santos, M. F. A., Almeida, M. R. A., Mota, F. C., Gomes, A. C. M. M., and Tigano, M. S. 2008b. Diversity of Meloidogyne arenaria using morphological, cytological and molecular approaches. Nematology 10:819-834

Cetintas, R., Kaur, R., Brito, J. A., Mendes, M. L., Nyczepir, A. P., and Dickson, D. W. 2007. Pathogenicity and reproductive potential of Meloidogyne mayaguensis and $M$. floridensis compared with three common Meloidogyne spp. Nematropica 37: 21-31.

Cherry, T., Szalanski, A. L., Todd, T. C., and Powers, T. O. 1997. The internal transcribed spacer region of Belonolaimus (Nemata: Belonolaimidae). J. Nematol. 29:23-29.

Cofcewicz, E. T., Carneiro, R. M. D. G., Castagnone-Sereno, P., and Quénéhervé, P. 2004. Enzyme phenotypes and genetic diversity of root knot nematodes parasitizing Musa in Brazil. Nematology 6:85-95.

Davis, E. L., Rich, J. R., Gwynn, G. R., and Sisson, V. 1988. Greenhouse evaluation of Nicotiana spp. for resistance to root knot nematodes. Nematropica 18:99-107.

Díaz-Silveira, M. F., and Herrera, J. O. 1998. An overview of nematological problems in Cuba. Nematologica 28:151-164.

Di Vito, M., Lombardi, D. A., Zaccheo, G., and Catalano, F. 1998. Response of lines and cultivars of tobacco and Nicotiana species to Italian populations of Meloidogyne species. Nematol. Mediterr. 26:271-274.

Ferraz, L. C. C. B., and Brown, D. J. F. 2002. An Introduction to Nematodes: Plant Nematology. Pensoft Publishers, Sofia, Bulgaria. 
Figueiredo, M. B. 1958. Algumas obervações sobre os nematóides que atacam o fumo no estado de São Paulo. Rev. Agric. 33:69-73.

Gomes, C. B., Couto, M. E. O., and Carneiro, R. M. D. G. 2008. Registro de ocorrência de Meloidogyne mayaguensis em goiabeira e fumo no sul do Brasil. Nematol. Bras. 32:244-247.

Handoo, Z. A., Skantar, A. M., Carta, L. K., and Erbe, E. F. 2005. Morphological and molecular characterization of a new root-knot nematode, Meloidogyne thailandica n. sp. (Nematoda: Meloidogynidae), parasitizing ginger (Zingiber sp.). J. Nematol. 37:342-353.

Hartman, K. M., and Sasser, J. N. 1985. Identification of Meloidogyne species on the basis of differential host and perineal pattern morphology. Pages 68-69 in: An Advanced Treatise on Meloidogyne. Vol. II: Methodology. K. R. Barker, C. C. Carter, and J. N. Sasser, eds. North Carolina State University, Raleigh.

Hugall, A., Stanton, J., and Moritz, C. 1999. Reticulate evolution and the origins of ribosomal internal transcribed spacer diversity in apomitic Meloidogyne. Mol. Biol. Evol. 16:157-164.

Hussey, R. S., and Barker, K. R. 1973. A comparison of methods of collecting inocula for Meloidogyne spp., including a new technique. Plant Dis. Rep. 57: 1025-1028.

Johnson, C. S., Way, J., and Barker, K. R. 2005. Nematode parasites of tobacco. Pages 675-708 in: Plant Parasitic Nematodes in Subtropical and Tropical Agriculture. M. Luc, R. A. Sikora, and J. Bridge, eds. CABI International, St. Albans, UK

Lima, I. M., Souza, R. M., Silva, C. P., and Carneiro, R. M. G. 2005. Meloidogyne spp. from preserved areas of Atlantic Forest in the State of Rio de Janeiro, Brazil. Nematol. Bras. 29:31-38.

McClure, M. A., Nischwitz, C., Skantar, A. M., Schmmit, M. E., and Subbotin, S. A. 2012. Root-knot nematodes in golf course greens of the western United States. Plant Dis. 96:635-647.

Mes, T. H. M., and Cornelissen, A. W. C. A. 2004. Non-homogenized ITS regions in the parasitic nematode Cooperia oncophora. Parasitology 129:213-222.

Moens, M., Perry, R. N., and Star, J. L. 2010. Meloidogyne species-A diverse group of novel and important plant parasites. Pages 1-13 in: Root-Knot Nematodes. M. Moens, R. N. Perry, and J. L. Star, eds. CABI International, Wallingford, UK.

Nicholas, K. B., Nicholas, H. B., Jr., and Deerfield, D. W., II. 1997. GeneDoc, analysis and visualization of genetic variation. EMBNEW NEWS 4:14.

Nono-Womdim, R., Swai, I. S., Mrosso, L. K., Chadha, M. L., and Opeña, R. T. 2002. Identification of root-knot nematode species occurring on tomatoes in Tanzania and resistant lines for their control. Plant Dis. 86:127-130.

Ogbuji, O. R. 1981. Variations in infectivity among populations of Meloidogyne javanica on tobacco and pepper. Plant Dis. 65:65-66.

Rammah, A., and Hirschmann, H. 1988. Meloidogyne mayaguensis n. sp. (Meloidogynidae), a root knot nematode from Puerto Rico. J. Nematol. 20:58-69.
Randig, O., Bongiovanni, M., Carneiro, R. M. D. G., and Castagnone-Sereno, P. 2002. Genetic diversity of root-knot nematodes from Brazil and development of Scar markers specific for the coffee-damaging species. Genome 45:862-870

R Development Core Team. 2012. R: A Language and Environment for Statistical Computing. Online publication. R Foundation for Statistical Computing, Vienna. http://www.R-project.org

Rich, J. R., and Garcia, M. R. 1985. Nature of the root knot disease in Florida tobacco. Plant Dis. 69:972-974.

Shew, H. D., and Lucas, G. B. 1991. Compendium of Tobacco Diseases. American Phytopathological Society, St. Paul, MN.

Siddiqi, M. R., ed. 2000. Tylenchida Parasites of Plants and Insects, 2nd ed. CABI Publishing, Wallingford, UK.

Sinditabaco. 2013. Online publication. Sindicato Interestadual da Indústria do Tabaco. http://www.sindifumo.com.br

Souza Cruz. 2013. Online publication. http://www.souzacruz.com.br

Stanton, J. M., McNicol, C. D., and Steele, V. 1998. Non-manual lysis of secondstage Meloidogyne juveniles for identification of pure and mixed samples based on the polymerase chain reaction. Australas. Plant Pathol. 27:112-115.

Stanton, J. M., O’Brien, P. C., Schipke, L. G., Hugall, A., and Moritz, C. 1992 Species of root-knot nematode (Meloidogyne spp.) affecting tobacco in north Queensland, including two new host races of $M$. arenaria. Australas. Plant Pathol. 21:150-157.

Tamura, K., Peterson, D., Perterson, N., Stecher, G., Nei, M., and Kumar, S. 2011. Mega 5: Molecular evolutionary genetics analysis using maximum likelihood, evolutionary distance, and maximum parsimony methods. Mol. Biol. Evol. 28: 2731-2739.

Thompson, J. D., Gibson, T. J., Plewniak, F., Jeanmougin, F., and Higgins, D. G 1997. The Clustal X windows interface, flexible strategies for multiple sequence alignment aided by quality analysis tools. Nucleic Acids Res. 25: 4876-4882.

Trudgill, D. L., and Blok, V. C. 2001. Apomitic, polyphagous root knot nematodes Exceptionally Successful and damaging biotrophic root pathogens. Annu. Rev. Phytopathol. 39:53-77.

Yang, B., and Eisenback, J. D. 1983. Meloidogyne enterolobii n. sp. (Meloidogynidae) a root knot nematode parasitizing Pacara earpod tree in China. J. Nematol. 15: 381-391.

Yi, H. Y., Ruft, R. C., Wernsman, E. A., and Conkling, M. C. 1998. Mapping the root knot nematode resistance gene $(R k)$ in Tobacco with RAPD markers. Plant Dis. 82:1319-1322.

Zem, A. C., Zanon, J. I., and Monteiro, A. R. 1985. Nota sobre a ocorrência de nematóides associados à cultura do fumo no Estado de Santa Catarina e Rio Grande do Sul. Page 62 in: Reunião Brasileira de Nematalogia, 9. Resumos Sociedade Brasileira de Nematologia/Copersucar, Piracicaba, SP, Brazil. 